\title{
SEISMIC DAMAGE ASSESSMENT OF LIFELINES BASED ON GEOSPATIAL ANALYSIS
}

\author{
M. Eskandari ${ }^{1}$, S. Goodarzi ${ }^{2}$, M. A. Nekooie $^{3}$ \\ ${ }^{1}$ Department of GIS, Malek Ashtar University of Technology, 15875-1774 Tehran, Iran. \\ eskandarim@mut.ac.ir \\ 2 Department of Industrial Management, Shahid Beheshti University, Tehran, Iran. \\ sa.godarzi.ra@gmail.com \\ ${ }^{3}$ Department of GIS, Malek Ashtar University of Technology, 15875-1774 Tehran, Iran. \\ nekooie@mut.ac.ir
}

KEY WORDS: Seismic Disaster, Spatial Analysis, GIS, Monte Carlo Simulation

\begin{abstract}
:
The main purpose of this study is to develop a Geospatial Information System (GIS) model with the ability to assess the seismic damage to lifelines for two well-known hazards, including ground shaking and ground failure simultaneously. The model that is developed and used in this study includes four main parts of database implementation, seismic hazard analysis, vulnerability assessment and seismic damage assessment to determine the lifeline's damage probability. To consider uncertainty analysis in the model, Monte Carlo simulation is used based on 10,000 iterations. The results of hazard analysis indicated that peak ground acceleration is about $0.03 \mathrm{~g}$ to $0.3 \mathrm{~g}$ and there is slight to moderate damages to the desired infrastructure in the study area.
\end{abstract}

\section{INTRODUCTION}

Earthquakes are one of the most destructive natural hazards and cause casualties as well as financial and environmental damage every year around the world. As Iran is a seismic country located over the Himalayan-Alpied seismic belt, there is a high possibility of earthquake occurrence (Yazdani and Kowsari 2011).

In modern societies, the civil infrastructure and utility systems are very important to support daily activities and achieve socioeconomic prosperity. Because these services are necessary for emergency services and are critical for survival, the loss of utility systems can have calamitous consequences for a community who is trying to recover after a seismic event. Relevant networks, such as the water, electricity, communication and transportation systems, which are often termed lifelines, are inherently complex and like most manmade structures, often prone to seismic events.

Lifelines are crucial lines for the survival of urbanization in the modern world. These lifelines are used to produce and distribute goods and services in urban units, and life possibility in cities depends on the quality and the quantity of these lifelines' function. Therefore, seismic vulnerability of critical infrastructures is very important as damages to these infrastructures (as well as being a part of the damage) can make the other disaster-related damages harsher and affect the recovery period.

The usage of geographic information systems (GIS) has been used for a wide number of different types of vulnerability assessments and analyses. Some researchers such as Karlson (2012), Rezaie and Panahi (2015), Armas (2012), Hizbaron et al. (2012), Servi (2004) and Sinha et al. (2016) have used geospatial information system GIS-based multi criteria decision-making methods.
On this basis, initially the literature review on the seismic damage analysis of lifeline is investigated; and then a brief introduction to research methodology in the form of seismic hazard relations, seismic vulnerability functions and damage analysis relations of lifelines and also the Monte Carlo Simulation methods are presented. Finally, the results and conclusions of the proposed model have been discussed.

\section{LITERATURE REVIEW}

Extensive research has been recently conducted about understanding the response of a complex urban lifeline system under external perturbations. Analytical system reliability frameworks are being used frequently to estimate the probabilities of complex system events (Dotson and Gobien 1979; Kang et al. 2008; Li and He 2002; Song and Der Kiureghian 2003; Theologou and Carlier 1991; Yoo and Deo 1988), while others utilize the simulation models to predict the seismic performance of a lifeline network (Hwang et al. 1998; Shinozuka et al. 2007). In general, analytical approaches incorporate the vulnerability of the components represented by fragility curves in a system level analysis.

In general, vulnerability assessment methods are divided into two groups: experimental and analytical methods. The empirical methods for the seismic vulnerability assessment can be divided into two main groups: (1) damage probability matrices (DPM) and (2) vulnerability functions (Calvi et al. 2006). Various models such as HAZUS 99 (FEMA 1999), Risk-Ue Project (Mouroux and Le Brun 2006), JICA (2000), LESSLOSS (2007), etc. based on vulnerability functions were presented. Also many researchers have studied earthquake damage analysis for complex infrastructure systems (Tan and Shinozuka 1982; Vanzi 1996; Hwang et al. 1998; Davis et al. 2000; Cagnan and Davidson 2003; Shinozuka et al. 2007). 
In general, there is a lack of consideration of the existing uncertainties in the estimation of seismic damage in the previous studies.

Hwang et al. (1998) evaluated the seismic performance of the water delivery network of Shelby County in Tennessee. SelcukKestel et al. (2012) developed a GIS-based model to show the seismic reliability of lifelines based on a network reliability algorithm and presenting upper and lower values of system reliability using seismic hazard and network information.

However, the relationships between seismic damage analysis of lifelines and spatial information systems have not been adequately investigated and only a few models to assess the damage of lifelines based on GIS are available.
The descriptive and spatial information related to geology and seismicity play an important role in the seismic damage analysis of the infrastructure. Hence, developing a model in an appropriate environment, such as the geo-spatial information system, is an essential requirement. Modeling can be defined as a simplification of the real world and is accomplished using GIS to provide a set of map layers and the relations between them. All the necessary steps to implement this model in the seismic loss estimation of the infrastructure are shown in Figure1 and the procedures are explained.

The desired model includes a three-layered structure as database layer, logic layer, and presentation layer. It is important to note that the model that is used in this study uses two main libraries of ArcGIS Engine and NET Frameworks for reading and writing files and spatial processing on the data. The following section includes all of the necessary steps to implement our model in the seismic damage analysis of lifeline.

\section{MATERIALS AND METHODS}

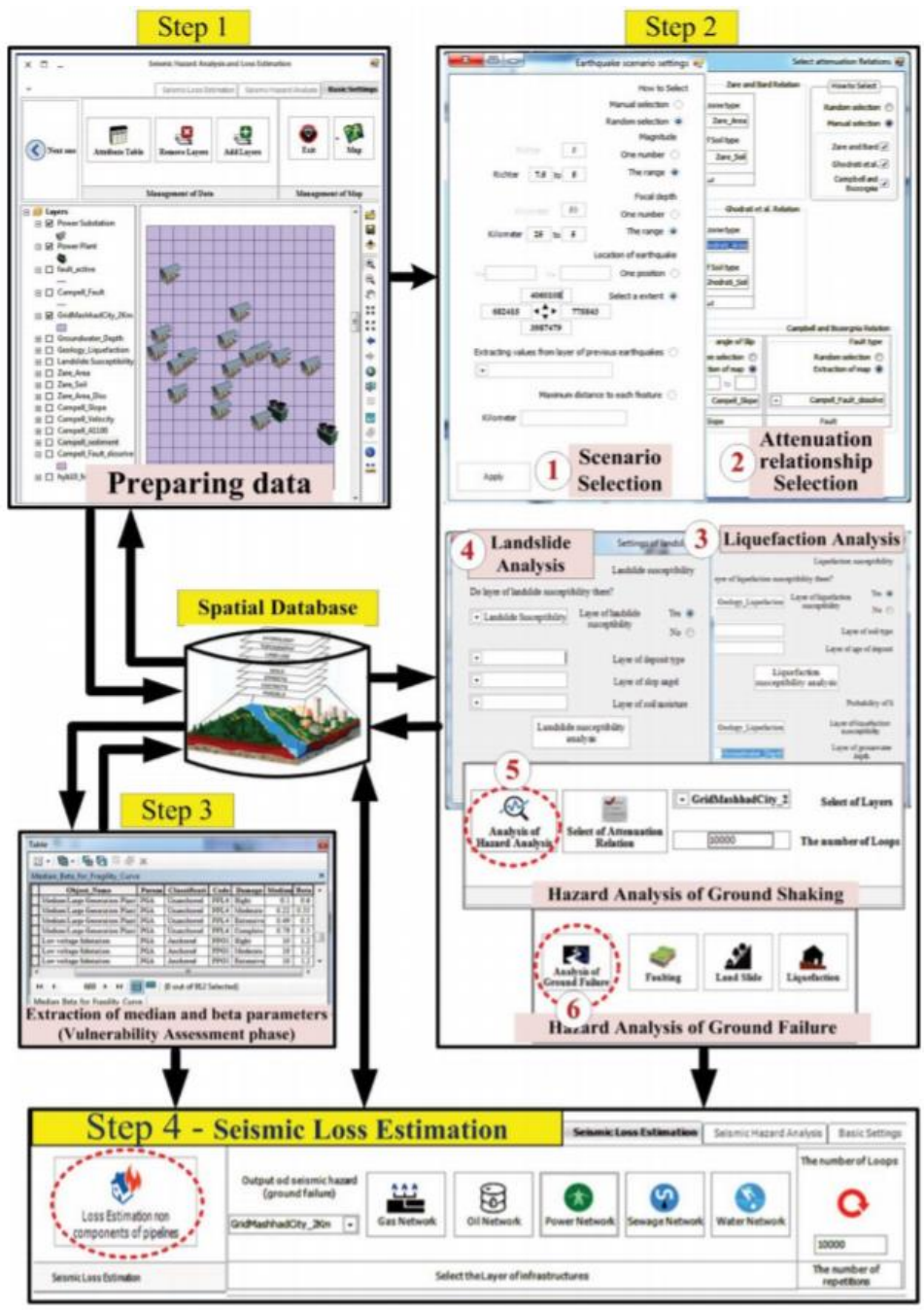

Figure1. Proposed systematic procedure of earthquake damage assessment 


\subsection{Step 1- Implement the Database}

The required criteria to select the database of the management system should be able to support spatial data (including vector and raster), work with big data, communicate with programming environment and simultaneously service multiple users. According to the above-mentioned criteria, the local database of ESRI, termed the geo-database, is used in this study. On this basis, the infrastructure data for a city in Iran with a high potential earthquake are collected to be applied in damage analysis.

Hence, the ESRI local database is used with the following GIS layers;

- Vector layers of water, electricity, gas, and oil networks including but not limited to water pumping stations, water storages, water treatment plant, wells, power plants, substations with different voltage, compressor stations and CGS; oil tank farm, gas stations;

- Descriptive layer of each infrastructure such as production volume, with anchored or unanchored components and etc. (Statistical Center of Iran 2014);

- Vector layer related to the location of the faults and historical and instrumental earthquake around the study area (Berberian and Yeats 1999; Falcon 1983);

- Geological vector layer including groundwater depth, deposit type, geological age, slope angle, and soil moisture;

- Vector layer for liquefaction susceptibility and landslide susceptibility of the region;

- Descriptive layer for parameters of attenuation relations used in the analysis;

- The median and beta descriptive layers of fragility curve for each component of infrastructures.

\subsection{Step 2- Seismic hazard analysis}

Seismic hazard analysis is an essential step in the analysis of seismic damage to build critical infrastructures. In this regard, the earthquake hazards can be divided into two main categories as GS and GF. GF is further divided into three different types including faulting, landslide and liquefaction. It should be mentioned that the liquefaction failure is also further divided into two categories as lateral spreading and ground settlement (FEMA 2011). Based on the model that is used in this study, the GS and GF are discussed, and the necessary steps to estimate the seismic hazard are presented in the following.

- Earthquake magnitude: Historical and instrumental earthquakes indicated that there were earthquakes with a high magnitude at different times inside and around the desired case study (at least eight historical earthquake and the three instrumental earthquakes between 6 and 7.5 degree on Richter scale in a distance less than $100 \mathrm{~km}$ from center of the metropolis), as well as numerous earthquakes with smaller scale between 4 and 6 on the Richter scale. Accordingly, in order to cover the majority of earthquakes in the study area, the possible magnitude is randomly selected in the range of 5 to 7.5 on the Richter scale based on a uniform distribution function.

- Focal depth: Given that more than 85 percent of previous earthquakes in this region have occurred at a depth between 5 and $25 \mathrm{~km}$ and 15 percent of previous earthquakes in this region have occurred at a depth between 25 and $75 \mathrm{~km}$ (Mirzaei et al. 2002), the focal depth of the earthquake is selected at a random intervals between 5 to $25 \mathrm{~km}$ based on a uniform distribution function.

- Location of the earthquake: Location of the earthquake is assumed that they happen at the same historical locations, instrumental earthquakes, or active faults in the region. The system randomly choose a location from the available data points based on uniform distribution function as an extent of the map with a radius of $150 \mathrm{~km}$ around the city.

\subsubsection{Hazard Analysis for ground shaking}

Hazard analysis for ground shaking using attenuation relationships Many factors, including the fault mechanism, site geological conditions, thickness and type of overburden, affect the attenuation of ground motion, and the most recent attenuation laws also take these effects into account. In this study, the Zare et al. (1999) and Ghodrati et al. (2007) relationships are used for hazard analysis.

\subsubsection{Hazard analysis for Ground Failure}

Up to this step, ground shaking was discussed. In this step, the ground failure which is divided into three main categorizes as liquefaction, landslide, and faulting, are considered and analyzed by using various algorithms.

3.2.2.1 Liquefaction: Liquefaction happens when a saturated soil loses a substantial amount of strength due to the high excess pore-water pressure generated and accumulated during strong earthquake GS. In order to consider the damage caused by soil liquefaction, the following steps are taken in this study:

- Preparing the geological map

- Determining liquefaction susceptibility (Youd and Perkins 1978)

- Determining liquefaction probability (FEMA 2011)

- Determining the peak ground displacements of lateral spreading due to liquefaction (Boore 1987)

- Determining the peak ground displacement of ground settlement due to liquefaction (Tokimatsu and Seed 1987).

3.2.2.2 Landslide: The following steps needs to be taken to estimate the permanent displacement due to the landslide:

- Determination of Liquefaction Susceptibility (Keefer and Wilson 1989),

- Determination of Critical Accelerations based on Susceptibility Categories (Keefer and Wilson 1989),

- Determination of area percentage of Map with a Landslide-Susceptible Deposit (Wieczorek et al. 2013),

- Determination of Permanent Ground Displacements.

3.2.2.3 Faulting: The third and last factor is faulting which its median maximum displacement (MD) is evaluated using the following equation (Wells and Coppersmith 1994):

$$
\log (M D)=-5.26+0.79 \times M
$$


In this equation, $\mathrm{MD}$ is median maximum displacement and $\mathrm{M}$ is magnitude Step 2 is repeated for all grids in the designed system to estimate the PGA, PGV, PGD and peak ground displacement due to Lateral Spreading, Ground settlement, and landslides for each grid.

\subsection{Step 3- Seismic Vulnerability Functions Extraction}

The seismic vulnerability of a structure is defined as its susceptibility to damage by GS or GF with a given intensity (Omidvar and Kivi 2016). The seismic vulnerability assessment of an infrastructure requires fragility models for many different components. A fragility models will be resulted in fragility curves to describe the probability of reaching or exceeding different damage states given peak structure response (Pitilakis and Argyroudis 2014).

Based on the methodology provided by HAZUS, all vulnerability functions for water, power, oil, and gas networks are given to the model for each damage state. Vulnerability functions are composed of two parameters as Median which is used for any component reaches the threshold of damage state, and Beta or Standard Deviation that is based on the type of hazards (ground shaking or ground failure). According to the anchored or unanchored and the type of components, median and Beta parameters are called from model. Damage presented by fragility curves are consisted of five states including $\mathrm{ds}_{1}$ (Non-damage), $\mathrm{ds}_{2}$ (Slight), ds $\mathrm{s}_{3}$ (Moderate), $\mathrm{ds}_{4}$ (Extensive), and $\mathrm{ds}_{5}$ (Complete) (FEMA. 2011).

\subsection{Step 4- Seismic Damage Analysis}

The proposed loss estimation methods provide damage estimations and service outages for lifelines with minimum operations. The direct output (damage estimate), based on using the fragility curves as an input for the model, calculates the probability of damage exceeding a damage state for the given level of GS. Then, this output will be used directly as an input in the loss estimation method or combined with inventory information to predict the distribution of damage as a function of the type of facility and geographical location.

It is important to note that heavy components of the network are very vulnerable to the maximum ground acceleration (PGA). For infrastructure damages, considering the PGA or PGD, the probability of being in or exceeding a damage state, $d s$ is modeled as follows (FEMA. 2011):

$$
\begin{aligned}
& P_{\text {Groundshaking }}[\text { ds } \mid P G A]=\Phi\left[\frac{1}{\beta} * \operatorname{Ln}\left(\frac{P G A}{\overline{P G A}}\right)\right](9) \\
& P_{\text {GroundFailure }}[d s \mid P G D]=\Phi\left[\frac{1}{\beta} * \operatorname{Ln}\left(\frac{P G D}{\overline{P G D}}\right)\right](10)
\end{aligned}
$$

Where, $\overline{P G A}$ or $\overline{P G D}$ is the median value of the PGA or PGD any infrastructure components reaches the threshold of the damage state, $d_{s}, \beta$ is the standard deviation of the natural logarithm of spectral displacement of damage state, $d_{s}$, and $\varphi$ is the standard normal cumulative distribution function.
The damage results for both ground shaking and ground failure are combined based on the probability rules of union and intersection of two events. For example, the probability of exceeding a given damage state is slight for combined GF and GS failures according to eq. 11 (FEMA. 2011). Other damage states are combined in this way.

$$
P_{C O M B}[d s \geq S]=P_{G F}[d s \geq S]+P_{G S}[d s \geq S]-
$$$$
P_{G F}[d s \geq S] * P_{G S}[d s \geq S]
$$

Where, $\mathrm{d}_{\mathrm{S}}$ is damage state, and $\mathrm{S}$ indicate Slight damage. COMB indicates the combined probability for the damage state due to occurrence of ground failure or ground shaking. At this stage, the damage is analyzed as cumulative. Therefore, probabilities of the damage based on non-damage probability of equations 12 and 13 and the slight damage probability can be calculated and the other probabilities are discrete in this way (FEMA. 2011).

$$
\begin{aligned}
& P_{\text {COMB }}[d s=\text { Non Damage }]=1-P_{\text {СOMB }}[d s \geq \\
& S]
\end{aligned}
$$

$$
\begin{aligned}
& P_{\text {COMB }}[d s=\text { Slight }]=P_{\text {СОMB }}[d s \geq S]+ \\
& P_{\text {COMB }}[d s \geq M]
\end{aligned}
$$

All these steps are repeated for all features. The whole process is repeated once for 10,000 times for Monte Carlo Sampling to consider the uncertainty in the model.

\section{RESULTS AND DISCUSSION}

Seismic hazard analysis was carried out using non-probabilistic and probabilistic methods and the output of the model are presented in the form of zoning map based on MCS (Figure 2). The results of seismic hazards using the MCS method shows PGA varies from $0.03 \mathrm{~g}$ to $0.3 \mathrm{~g}$ which indicates the area exposed with high hazard levels (Figure 2). These results confirm that the PGA is not trended in any particular side.

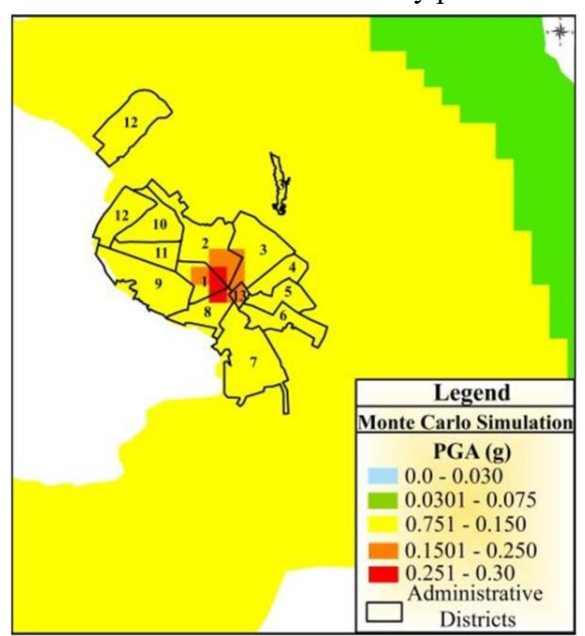

Figure 2. Zoning map of Seismic hazard analysis 
The zoning maps of liquefaction and landslide susceptibility are shown in the Figure 3. It should be noted that these maps are not relevant to the earthquake scenarios and they are dependent only on the geological characteristics of study area. It is also important to note that based on evaluated zoning map, there is moderate potential of liquefaction and low potential of landslide for the desired area. Because of the high number of outputs, the zoning maps of permanent ground displacement of lateral spreading are shown in the Figure 8 . The results shows PGD varies from 0 inch to 15 inch which indicates the area exposed with medium hazard levels (Figure 4).

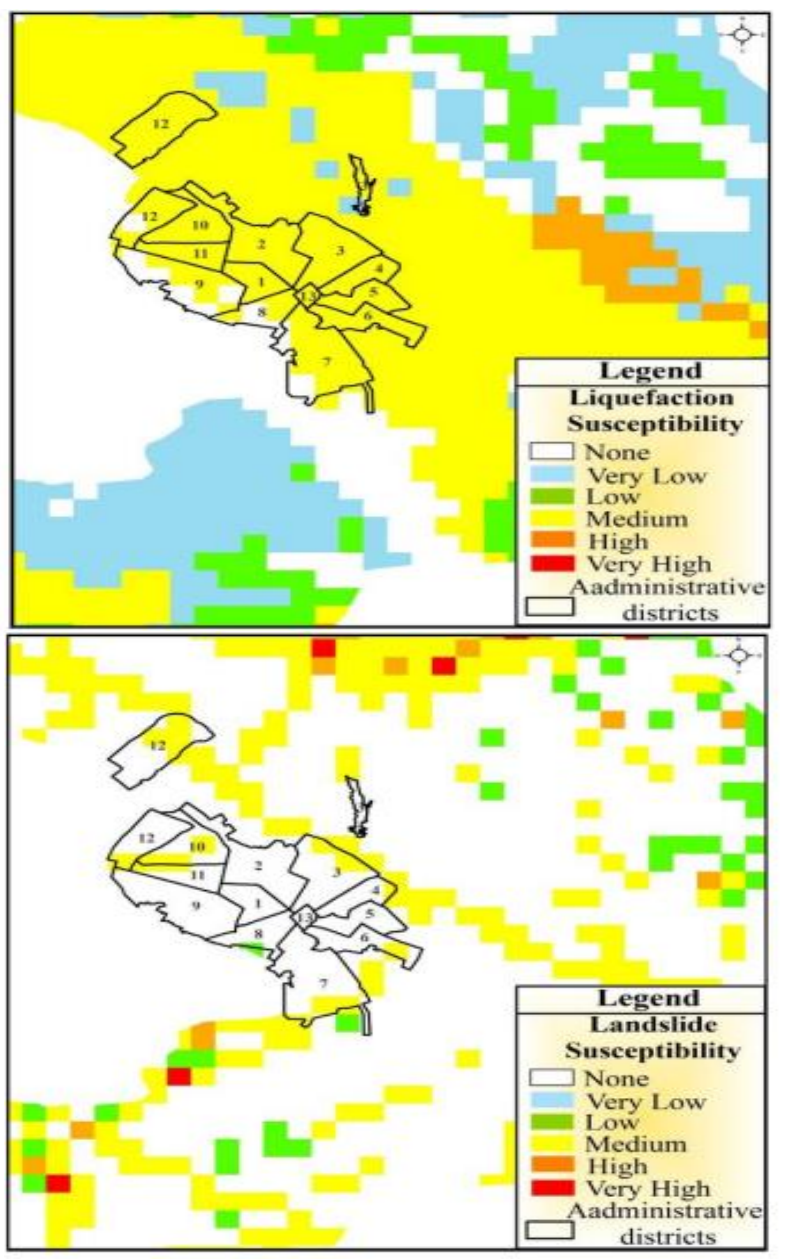

Figure 3. Liquefaction and landslide susceptibility zoning maps

After determining seismic hazard maps of the study area, the seismic damage analysis maps were prepared for various infrastructures and the results are presented in Figure 5. The seismic damage map for two elements is shown in five damage states, including, Non, slight, moderate, extensive and complete for MCS method. For example, the greatest damage is for pumping stations, wells, water storages and water treatment plants, respectively. The least damage to the water network is related to the water treatment plants and maximum damages to the water networks are for water pumping stations.

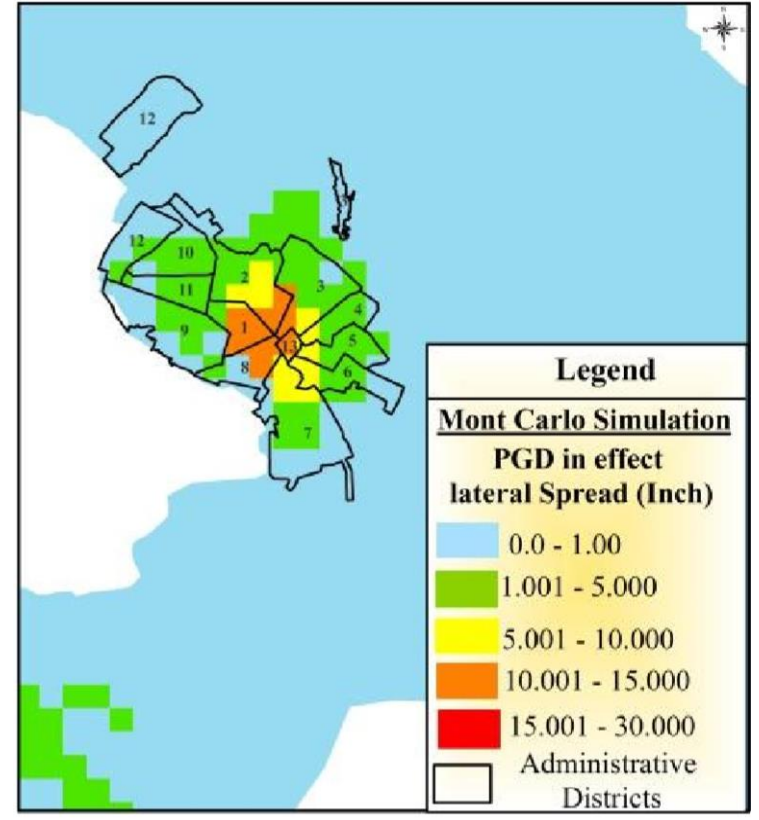

Figure 4. Zoning map of lateral spread

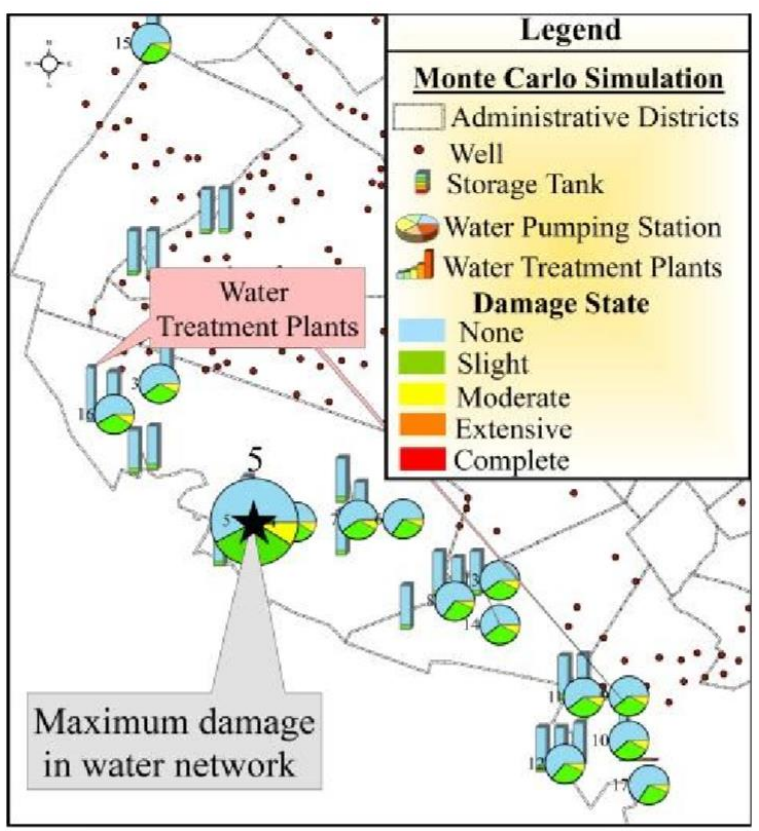

Figure 5. Seismic damage analysis map of the water network

\section{CONCLUSIONS}

Based on the seismic damage and seismic hazard analyses, six different outputs were calculated using Monte Carlo simulation with 10,000 iterations as: (1) peak ground velocity (PGA), (2) PGV, (3) PGD, (4) PGD due to vertical settlement, (5) PGD due to lateral spread and (6) PGD due to landslide. Each of these outputs was used in the earthquake loss estimation of the system. In the case of damage analysis, the probability of seismic damage for GS and GF hazards was independently determined. 
Then, these probabilities were combined with the probability rules of union and intersection of two events, and, finally, the seismic damage probability was determined for each component of the infrastructure for the five different damage states (none, slight, moderate, extensive and complete). It should be mentioned that for the seismic damage analysis, different parameters and relations, such as the descriptive and spatial data of each infrastructure, regional geological information, various attenuation relations, the median and beta parameters of the fragility curve for the GS hazard, vertical settlement, lateral spreading and landslides, and other different relations for seismic hazard and damage analysis were used.

Permanent ground displacement due to lateral spreading is within the range of 0 to 15 inches in this case study. The results also show Gas Stations, Power Plants, Power Substations, and Water Pumping Stations got the greatest damages and Water Treatments had the least damage. For example, the slight damage probability of the gas station is $25 \%$. In addition, the slight damage probability to the power plants, power substations and gas stations is $21 \%, 18 \%$, and $15 \%$. It should be mentioned that the infrastructures with higher damage were mainly located at nine urban areas in the study area.

\section{REFERENCES}

Yazdani A, Kowsari M. 2011. Statistical prediction of the sequence of large earthquakes in Iran. Int J Eng-Trans B. 24:325-336. (Persian)

Karlson M. 2012. Assessing GIS-based indicator methodology for analyzing the physical vulnerability of water and sanitation infrastructure [Water and Environmental Studies]. [master thesis], Water and Environmental Studies. Link€oping, Zweden: Linkopings University; p. 42.

Rezaie F, Panahi M. 2015. GIS modeling of seismic vulnerability of residential fabrics considering geotechnical, structural, social and physical distance indicators in Tehran using multi-criteria decision-making techniques. Nat Hazards Earth Syst Sci. 15:461-474.

Armas I. , 2012. Multi-criteria vulnerability analysis to earthquake hazard of Bucharest, Romania. Nat Hazards. 63:1129-1156.

Hizbaron DR, Baiquni M, Sartohadi J, Rijanta R. 2012. Urban vulnerability in Bantul District, Indonesia - towards safer and sustainable development. Sustainability. 4:2022-2037.

Servi M. 2004. Assessment of vulnerability to earthquake hazards using spatial multicriteria analysis: Odunpazari, Eskisehir case study [master thesis]. Turkey: Middle East Technical University. p. 94.

Sinha N, Priyanka N, Joshi P. 2016. Using spatial multi-criteria analysis and ranking tool (SMART) in earthquake risk assessment: a case study of Delhi region, India. Geomatics Nat Hazards Risk. 7:680-701.
Calvi GM, Pinho R, Magenes G, Bommer JJ, Restrepo-Velez LF, Crowley H. 2006. Development of seismic vulnerability assessment methodologies over the past 30 years. ISET J EarthqTechnol. 43:75-104.

Mouroux P, Le Brun B. 2006. Risk-ue project: an advanced approach to earthquake risk scenarios with application to different European towns. In: Sousa OC, Antoni R, Xavier G, editor(s). Assessing and managing earthquake risk: geoscientific and engineering knowledge for earthquake risk mitigation: developments, tools, techniques. Dordrecht: Springer; p. 479-508.

[JICA] [Japan International Cooperation Agency]. 2000. The study on seismic microzoning of the Greater Tehran Area in the Islamic Republic of Iran. In: Mae I, editor. Pacific Consultants International Report. Japan: OYO Cooperation. p. 29-34.

LESSLOSS. 2007. Prediction of ground motion and loss scenarios for selected infrastructues systems in European Urban Environments. In Faccioli E, editor. Risk mitigation for earthquakes and landslides. Italy: IUSS Press; p. 9- 24.

Shinozuka M, Dong X, Chen TC, Jin X. 2007. Seismic performance of electric transmission network under component failures. Earthq Eng Struct Dyn. 36:227-244.

Vanzi I. 1996. Seismic reliability of electric power networks: methodology and application. Struct Saf. 18:311-327.

Cagnan Z, Davidson R. 2003. Post-earthquake lifeline service restoration modeling. In: Beavers JE, editor. Proceedings of the Sixth US conference and workshop on Lifeline earthquake engineering. August 10-13; Long Beach, California: American Society of Civil Engineers. p. 255-264.

Davis PM, Rubinstein JL, Liu KH, Gao SS, Knopoff L. 2000. Northridge earthquake damage caused by geologic focusing of seismic waves. Science. 289:1746-1750.

Boore DM. 1987. The prediction of strong ground motion. In: Erdik M, Toks $€$ oz MN, editor(s). Strong ground motion seismology: NATO Advanced Studies Institute series. Dordrecht: Springer. p. 109-141.

Youd TL, Perkins DM. 1978. Mapping liquefaction-induced ground failure potential. J Soil Mech Found Div. 104:433- 446.

Tokimatsu K, Seed HB. 1987. Evaluation of settlements in sands due to earthquake shaking. J Geotech Eng. 113:861- 878.

Omidvar B, Kivi HK. 2016. Multi-hazard failure probability analysis of gas pipelines for earthquake shaking, ground failure and fire following earthquake. Nat Hazards. 82:703-720.

Berberian, M., and Yeats, R.S. 1999. "Patterns of historical earthquake rupture in the Iranian Plateau." Bulletin of the Seismological society of America, 89(1), 120-139.

Dotson, W., and Gobien, J. 1979. "A new analysis technique for probabilistic graphs." IEEE Transactions on circuits and systems, 26(10), 855-865. 
Falcon, N.L. 1983. "A history of Persian earthquakes." The Geographical Journal, 149(3), 367-368.

FEMA. 2011. "HAZUS MH 2.0 Earthquake technical Manual." Department of Homeland Security, Washington, D.C. Unites States.

Ghodrati, G.A., Mahdavian, A., and Dana, F.M. 2007. "Attenuation Relationships for Iran." Journal of Earthquake Engineering, 11(4), 469-492.

Hwang, H.H., Lin, H., and Shinozuka, M. 1998. "Seismic performance assessment of water delivery systems." Journal of Infrastructure Systems, 4(3), 118-125.

Kang, W.-H., Song, J., and Gardoni, P. 2008. "Matrix-based system reliability method and applications to bridge networks." Reliability Engineering \& System Safety, 93(11), 1584-1593.

Keefer, D.K., and Wilson, R. 1989. "Predicting earthquakeinduced landslides, with emphasis on arid and semi-arid environments." Landslides in a semi-arid environment, 2(PART 1), 118-149.

Li, J., and He, J. 2002. "A recursive decomposition algorithm for network seismic reliability evaluation." Earthquake Engineering \& Structural Dynamics, 31(8), 1525-1539.

Mirzaei, N., Gheitanchi, M., Naserieh, S., Raeesi, M., Zarifi, Z., and Tabaei, S.-G. 2002. "Basic parameters of earthquakes in Iran." Danesh Negar Publ, Tehran, 37(2), 147-180. [persian].

Pitilakis, K., and Argyroudis, S. 2014. "Systemic Seismic Vulnerability and Risk Analysis of Urban Systems, Lifelines and Infrastructures." In Seismic Design of Industrial Facilities: Proceedings of the International Conference on Seismic Design of Industrial Facilities (SeDIF-Conference), Edited by S. Klinkel, C. Butenweg, G. Lin and B. Holtschoppen, Springer Fachmedien Wiesbaden, Wiesbaden.
Selcuk-Kestel, A.S., Duzgun, H.S., and Oduncuoglu, L. 2012. "A GIS-based software for lifeline reliability analysis under seismic hazard." Computers \& Geosciences, 42, 37-46.

Shinozuka, M., Dong, X., Chen, T.C., and Jin, X. 2007. "Seismic performance of electric transmission network under component failures." Earthquake Engineering \& Structural Dynamics, 36(2), 227-244.

Song, J., and Der Kiureghian, A. 2003. "Bounds on system reliability by linear programming." Journal of Engineering Mechanics, 129(6), 627-636.

Statistical Center of Iran 2014. "Iranian National Population and Housing Census in autumn 2011." The President's Office Deputy of Strategic Planning and Control,,, Iran [Persian].

Wells, D.L., and Coppersmith, K.J. 1994. "New empirical relationships among magnitude, rupture length, rupture width, rupture area, and surface displacement." Bulletin of the seismological Society of America, 84(4), 974-1002.

Wieczorek, G.F., Brown, W.M., Mark, R.K., Rice, P., and Alger, C.S. 2013. "La Honda Landslide Test Area, San Mateo County, California." In Landslides in Central California: San Francisco and Central California, July 20-29, 1989, Edited by, American Geophysical Union.

Yoo, Y.B., and Deo, N. 1988. "A comparison of algorithms for terminal-pair reliability." IEEE Transactions on Reliability, $37(2), 210-215$.

Zare, M., Bard, P.Y., and Ghafory-Ashtiany, M. 1999. "Site characterizations for the Iranian strong motion network." Soil Dynamics and Earthquake Engineering, 18(2), 101-123

Revised August 2019 